\title{
MARKETING PARA PROMOÇÃO DE PRODUTOS E SERVIÇOS DE INFORMAÇÃO: ESTUDO DE CASO DA BIBLIOTECA DA PRESIDÊNCIA DA REPUBLICA
}

\author{
Sofia Galvão Baptista \\ Maíra Murrieta Costa \\ Maria Altair Vilanova Viana Neta
}

\section{Resumo}

A aplicação da teoria de marketing como recurso gerencial para bibliotecas e serviços de informação é demonstrada por meio do caso da Biblioteca da Presidência da Republica, com o intuito de confirmar a validade da aplicação dos conceitos de marketing para a área social. Os serviços prestados pela biblioteca foram avaliados para observar o uso das atividades de promoção, relações públicas, merchandising, propaganda, incentivos, atmosfera e outras técnicas de marketing. Foi verificado que a biblioteca planejou e utilizou várias técnicas de promoção: atmosfera, divulgação dos serviços, relações públicas com projetos destinados a um determinado público, para promover seu relacionamento com o usuário da biblioteca.

Palavras-chave:

Marketing; Bibliotecas; Serviço de informação

\section{MARKETING FOR INFORMATION PRODUCTS AND SERVICES PROMOTION: BRASIL REPUBLIC PRESIDENCY LIBRARY' CASE STUDY}

\begin{abstract}
The application of the theory of marketing as management resource for libraries and information services is demonstrated by the Brasil Republic Presidency Library in order to confirm marketing concepts application for the social area. The services provided by the library was evaluated to observe the use of promotion activities, public relations, merchandising, advertising, incentives, atmosphere and others marketing techniques. It was found that the library planned and used various promotion techniques: atmosphere, services dissemination, public relations with projects aimed to an specific audience, and others actions to improve the user and the library relationship.
\end{abstract}

Keywords:

Marketing; Libraries; Information services

(C) Revista Digital de Biblioteconomia e Ciência da Informação,Campinas, v.6, n. 2, p. 83-104, jan./jun. 2009-ISSN: 1678-765X. 


\section{INTRODUÇÃO}

Marketing é propaganda? Marketing visa aumentar as vendas? Estas são as idéias freqüentemente associadas a marketing pelo público em geral. Pretende-se demonstrar nessa discussão que as premissas do marketing podem ser aplicadas às unidades de informação para a promoção de serviços de informação.

O marketing pode fornecer recursos para a área de serviços de informação. As ferramentas desenvolvidas para o setor lucrativo serão úteis para desenvolver produtos e serviços com base em necessidades de informação reais e identificadas, para comunicar ou esclarecer a clientela sobre novos produtos e serviços.

Razões para utilizar marketing:

- Marketing fornece um conjunto de técnicas e instrumentos que podem identificar: necessidades, desejos e preferências dos usuários;

- marketing força um questionamento sobre como a organização tem sido sensível aos problemas de busca de informação de seus usuários reais e potenciais, podendo causar uma mudança de ação dentro da biblioteca;

- marketing envolve uma administração dinâmica de relação de troca entre a biblioteca e seu público. Ao oferecer um produto ou serviço de informação, baseado nas necessidades identificadas, obtém-se o reconhecimento por meio do aumento da procura por seus serviços;

- marketing promove a comunicação, que é interessante para captar a atenção dos não usuários e fidelizar seus usuários reais. A comunicação ajuda a derrubar as barreiras geradas pelo desconhecimento sobre os serviços e produtos oferecidos e,

- marketing por meio da promoção poderá promover um maior uso dos serviços e produtos da biblioteca, bem como atrair mais investimentos para o aperfeiçoamento e oferta de novos serviços e produtos. 


\title{
2 ORIGEM DO MARKETING
}

O preconceito em relação ao marketing acontece pela sua origem. Inicialmente, a técnica foi utilizada para escoar o excesso de produção como atesta Manzo (1982, p. 41):

\begin{abstract}
Marketing teve origem na superprodução. Durante a $1^{\mathrm{a}}$. Guerra Mundial, a produção ficou concentrada em torno do conflito, não havendo quase produção de bens de consumo. Ao terminar a guerra, as indústrias voltaram a produzir normalmente, não havendo, ate então, dificuldade em colocar o produto no mercado, porque a procura era maior que a oferta. Esse sucesso provocou um imenso desenvolvimento industrial. Todos queriam produzir, e este fato, associado à crise econômica da época, gerou a depressão nos EUA. Foi nessa conjuntura que nasceu a prática do marketing [...] (MANZO, 1982, p. 41).
\end{abstract}

Dentro desse contexto, a definição existente, proposta pela American Marketing Association apud Churchill Júnior e Peter (2003, p.4), era a seguinte: “Marketing é a execução das atividades de negócios em que se encaminha o fluxo da mercadoria e de serviços, partindo do produtor até o consumidor final”.

Andreasen (1987) mostra os equívocos existentes entre marketing e venda e, sendo assim, marketing começou a ser confundido como armadilha ou "como melhor preparar armadilhas”. Na área da informação, pode-se ver o reflexo desse começo inadequado, quando Lima (1992), ironicamente, afirma que informação não é sabonete e que não deveria ser "vendida" como tal.

No entanto, temos outros autores como Amaral (1990, 1992a, 1992b), Baptista (1988), Silveira $(1986,1987)$ que a partir da década de 80 produziram uma série de artigos, mostrando que a técnica poderia ser utilizada para promover serviços de informação, com o objetivo de incrementar a relação usuário/ serviço.

Esses autores incentivavam a adoção da técnica, estratégia ou "filosofia” do marketing, mostrando que os resultados de sua aplicação são positivos para a promoção de serviços da área de informação.

A partir da década de 90, a Internet é considerada um novo canal de marketing (VASSOS, 1997; KOTLER, 1999; VIEIRA, NIQUE, 1999) e, as bibliotecas mais uma vez passaram a dispor desse novo canal de comunicação para interagir com o seu usuário.

(c) Revista Digital de Biblioteconomia e Ciência da Informação,Campinas, v.6, n. 2, p. 83-104, jan./jun. 2009- ISSN: 1678-765X. 
A Biblioteca central da Universidade de Brasília, por exemplo, teve a primeira versão de seu site disponibilizada para seus usuários em novembro de 1997 (COSTA, 2001). Sobre o potencial da Internet, autores como Bax (1998), Amaral (2004), dentre outros, reforçaram que as técnicas de marketing são positivas para a biblioteca e passaram a considerar a Internet como de fundamental importância para estas instituições.

\section{MARKETING SOCIAL}

Verifica-se, então, que, a partir de uma idéia essencialmente comercial, o marketing evolui para uma conotação mais ampla como, por exemplo, conotações sociais; o que provocou uma diferença entre marketing e venda, pois a venda se concentra nas necessidades do vendedor e o marketing nas necessidades do consumidor.

O desenvolvimento teórico do marketing recebeu contribuições dos conhecimentos das áreas da Sociologia, Antropologia, Estatística e Administração, não deixando de lado seus princípios fundamentais da Economia.

Depois de uma fase dedicada ao escoamento de produção, marketing passa a ser adotado por partidos políticos com problemas de imagem; por serviços de saúde tentando implantar uma prática ou modificar um hábito; por governos para mostrar suas realizações etc.

Kotler (1978) lança essas idéias em sua obra "Marketing para organizações que não visam o lucro". Nela, o autor mostra como promover campanhas para obter mudanças sociais e receber em troca o reconhecimento, incentivos e outras formas de aceitação. A obra evidencia o potencial do marketing para área social.

Exemplificando a proposta do autor, pode-se observar que as ações de esclarecimento podem envolver mudanças cognitivas, comportamento, valor dentre outras.

A mudança cognitiva acontece quando se esclarece o público, fornecendo informações de como proceder em determinadas situações. Por exemplo, no caso da implantação de uma nova lei. Na mudança de ação, espera-se uma mudança de atitude, por exemplo, o uso do cinto de segurança é obrigatório. 
Na mudança de comportamento, que implica numa alteração psicológica, de sentimentos ou de valores, é esperada uma mudança de hábito, por exemplo, campanhas educativas para paz no trânsito, se beber não dirija etc.

Essa lógica pode ser aplicada à utilização de catálogos de bibliotecas:

- $\quad$ mudança cognitiva - esclarecer sobre como usar os serviços de uma biblioteca;

- mudança de ação - usar o catálogo da biblioteca sempre que precisar de alguma informação sobre a coleção;

- mudança de comportamento - ter o hábito de ir diretamente ao catálogo toda vez que precisar de informações;

- mudança de valor - confiar na utilidade do catálogo para localizar informações.

As mudanças serão mais efetivas se estiverem correspondendo ao comportamento de busca do usuário. É imprescindível que se pergunte antes ao usuário, como ele procura a informação e o que gostaria de encontrar.

Baseando-se em Cronin (1981, p.386) apud Baptista (1985) tem-se a figura 1 que mostra o possível efeito de um ciclo promocional.
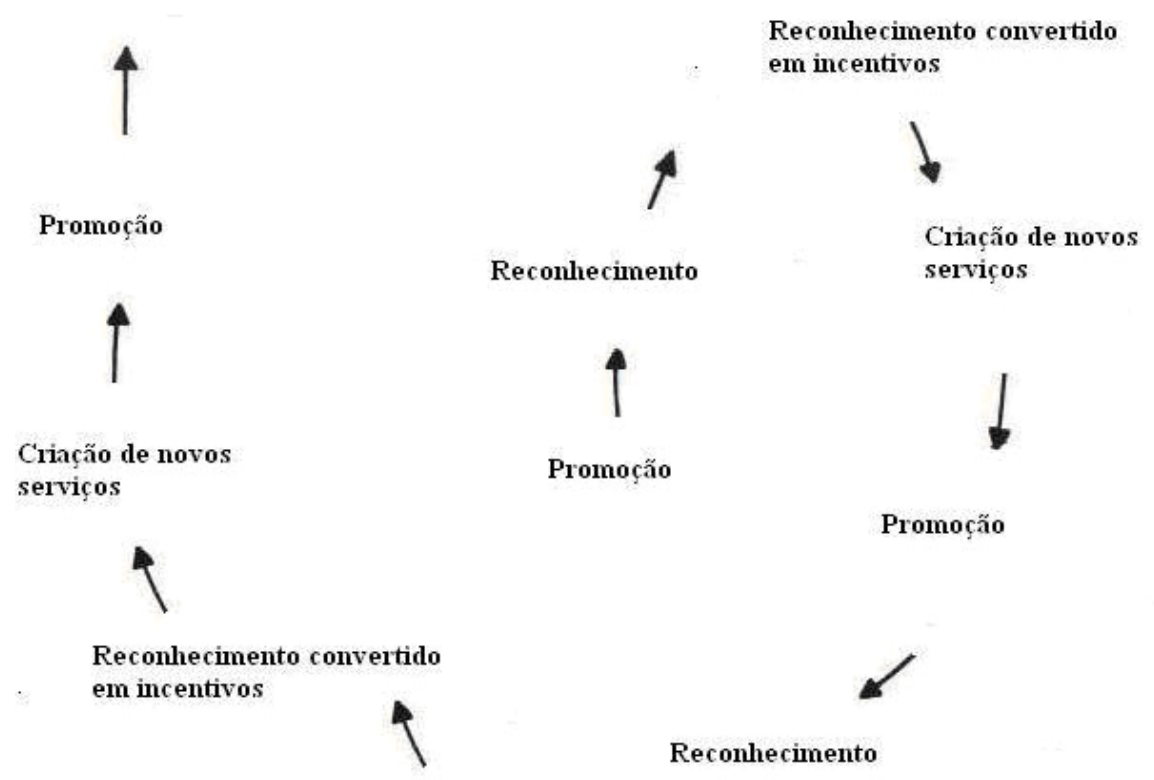

FIGURA 1 - CICLO DE PROMOÇÃO DE SERVIÇOS

Fonte: Cronin (1981, tradução nossa) 
O ponto fundamental do que é proposto, quando se fala na aplicação de marketing, é a receptividade do serviço por parte do usuário. A aceitação de um produto ou serviço será maior se o projeto for precedido de uma análise cuidadosa sobre o público-alvo e o ambiente em que este está inserido.

\section{COMO APLICAR MARKETING}

Inicialmente é feita uma análise sobre a atuação da unidade de informação, investiga-se tudo que possa impedir um melhor relacionamento entre a biblioteca e o seu públicoalvo. Em seguida, avalia-se o meio ambiente, identificando o público-alvo, o posicionamento da biblioteca em relação a outras instituições similares e o objetivo da organização.

Por fim, baseando-se numa análise cuidadosa das necessidades e desejos dos usuários, tomam-se decisões sobre o produto, como será promovido, comunicado e distribuído.

\subsection{Posicionamento no mercado ou estudo do meio ambiente que cerca a biblioteca}

A biblioteca deve se situar no seu meio ambiente interno e externo. Essa conscientização é importante para o planejamento estratégico da unidade e para o planejamento dos produtos e serviços de informação. O processo deve iniciar pela realização de algumas reflexões sobre a missão da unidade, a saber: qual é o seu principal público, quais as necessidades de informação do usuário preferencial e como ele será atendido. O meio ambiente que circunda a unidade de informação e a identificação dos aspectos que afetam o seu progresso.

Segundo Corrall (1994), a análise pode ser dividida em partes: (1) o ambiente macro (geral ou a área da indústria da informação a que a unidade pertence); (2) o ambiente da organização a que pertence e (3) o ambiente da própria unidade.

Para a análise ambiental, Corrall (1994) utiliza a sigla PEST (político, econômico, social e tecnológico) para identificar a análise das variáveis do macro e meio ambiente que influenciam a ação da unidade de informação.

(c) Revista Digital de Biblioteconomia e Ciência da Informação,Campinas, v.6, n. 2, p. 83-104, jan./jun. 2009- ISSN: 1678-765X. 
Além desses pontos, a análise deve incluir o posicionamento da biblioteca em relação a unidades similares para reforçar seu atendimento ou analisar a concorrência. No Brasil, existem poucas empresas comerciais que podem fornecer o mesmo serviço de uma biblioteca universitária, especializada ou pública, portanto, é difícil pensar em concorrência, mas se pode pensar em aliados.

\subsection{Público-alvo}

Em relação ao público-alvo, é necessário priorizar o atendimento deste, pois bibliotecas, em geral, tentam atender a $100 \%$ do público-alvo 100\% do tempo. Este procedimento gera produtos e serviços de informação genéricos, em vez de uma oferta direcionada para os diferentes segmentos que compõem este público. A prática da segmentação do público-alvo é feita de acordo com as especificidades dos usuários. Por exemplo: numa biblioteca universitária têm-se vários segmentos: professores, professores pesquisadores, alunos da graduação e alunos da pós-graduação. Pode-se, em cada segmento, identificar demandas diferenciadas para propósitos diferenciados.

Os leitores podem procurar informação em virtude de uma série de motivos, tais como: auto-desenvolvimento, atualização, dúvida momentânea, melhorar desempenho, treinamento, provas, concurso, lazer dentre outros. A biblioteca deve ter consciência da diversidade do potencial de produtos e serviços que pode oferecer.

As variáveis que podem ser utilizadas para diferenciar os usuários em uma biblioteca, dependendo de suas características, são as seguintes: demográficas (idade, sexo, ocupação, etc.); geográficas e psicográficas (atitudes, estilos de vida, etc) e muitas outras. Baptista(1988, p. 101).

Exemplos:

\section{Bibliotecas universitárias:}

Segmentação com base no perfil da comunidade acadêmica:

- estudantes; 
- professores;

- pessoal administrativo;

- administradores.

Segmentação com base na necessidade de informação:

- referência - localização de obras;

- $\quad$ serviço de disseminação seletiva da informação (SDI);

- buscas retrospectivas.

Segmentação baseada na atividade funcional dos usuários:

- instrução;

- pesquisa;

- administração.

Segmentação baseada na área de conhecimento:

- física;

- química;

- psicologia;

- sociologia etc.

Recomenda-se que o critério adotado possua as seguintes características:

- $\quad$ mensurável - capaz de oferecer informações específicas de interesse;

- acessível - no sentido de que biblioteca possa atingir facilmente o segmento e;

- substancial - amplo ou importante o suficiente.

Após a análise das informações obtidas, escolhe-se o segmento-alvo ou segmentos-alvo, pois, pode-se trabalhar como mais de um segmento. As necessidades, os desejos, as percepções, as preferências e a satisfação do grupo selecionado deverão ser investigadas. A forma mais direta para a obtenção dos dados é perguntar por meio de entrevistas ou 
questionários. Neste contexto, merece destaque o cuidado de utilizar amostras significativas. Para ilustrar, segue abaixo os itens que podem compor uma investigação:

- descrição de como obtém a informação;

- motivos que o levaram a utilizar o serviço da biblioteca;

- $\quad$ nível de satisfação;

- indicar os serviços que a biblioteca oferece, por ele conhecido;

- ordenar o serviço mais útil;

- fornecer sugestões para melhoria dos serviços etc.

Outros métodos para obter informações sobre como o usuário percebe e usa os serviços da biblioteca podem ser fornecidos, espontaneamente, pelos os usuários por meio de emails e outros meios de comunicação.

Tendo em mãos a avaliação do público-alvo, a biblioteca poderá então começar a planejar seus produtos e serviços. Forrest (2005) relata a experiência da Emory University (EUA) que reestruturou seus serviços em função da segmentação da comunidade a que servia. Eles criaram segmentos por área de conhecimento e pelo tipo de estudante, representaram essa segmentação organizacionalmente. Após essas ações, passaram a fornecer serviços e produtos adequados para cada subconjunto de usuários.

\subsection{Produtos e serviços}

O planejamento dos produtos ou serviços que serão disponibilizados deve oferecer uma base conceitual para definir a especialização do produto, seu desenvolvimento, recursos humanos e financeiros necessários e, principalmente, a compatibilidade com os dados levantados sobre a preferência do segmento - alvo. Com as mudanças tecnológicas, sociais, financeiras e outras do meio ambiente que cerca a unidade da informação, é necessário lembrar que esses produtos têm um ciclo de vida e que deverão, depois de certo período, ser reformulados, a partir de dados fornecidos pelos usuários.

\subsection{Valor de troca /preço}

(c) Revista Digital de Biblioteconomia e Ciência da Informação,Campinas, v.6, n. 2, p. 83-104, jan./jun. 2009- ISSN: 1678-765X. 
Na área de bibliotecas é raro, principalmente no Brasil, haver cobrança por produtos e serviços, excepcionalmente, o COMUT (Programa de Comutação Bibliográfica do IBICT) cobra seus serviços. Portanto, falar em preço, nem sempre faz parte do cotidiano dessas instituições. O esforço da biblioteca em atender as necessidades e preferências do seu público pode ter um retorno positivo por meio da procura do produto e serviço ou até um agradecimento verbalizado.

É possível, a partir de valores simbólicos, substituir o preço e gerar indicadores de satisfação do usuário. Por exemplo: uso do produto pelo leitor, reconhecimento, atenção ou qualquer outra forma de recompensa pelo esforço de atender as necessidades do usuário. O “valor”, da mesma forma que o preço, é uma medida para avaliar a aceitação do produto proposto.

Tem-se ainda, contra a cobrança por produtos e serviços dentro de uma biblioteca, a crença de que a informação é um bem público necessário para o funcionamento saudável de uma sociedade democrática. Aqueles que são a favor da cobrança argumentam que a tecnologia trouxe para as bibliotecas a necessidade de um maior investimento e que poucas bibliotecas têm condições de absorver tais custos. Cobrar ou não cobrar pode ficar a critério de cada biblioteca, de acordo com as suas possibilidades e objetivos.

\subsection{Promoção}

Amaral (2001, p76) define a promoção como a parte mais visível do marketing. Para a autora, os objetivos do emprego da promoção podem ser:

(1) tornar a unidade de informação e seus produtos e serviços conhecidos pelos usuários potenciais; (2) tornar o ambiente da unidade de informação e seus produtos e serviços atraentes para os usuários potenciais; (3) mostrar aos usuários reais como usar os produtos e serviços de informação; (4) evidenciar os benefícios dos produtos e serviços oferecidos; e (5) manter os usuários reais, constantemente, bem informados sobre a atuação da unidade de informação, seus produtos e serviços. (AMARAL, 2001, p.76).

A promoção pode ser feita de várias maneiras, por meio da propaganda, da publicidade, do contato pessoal, de incentivos e da atmosfera da organização. A promoção é considerada o canal de comunicação da organização para comunicar seus produtos e serviços.

(c) Revista Digital de Biblioteconomia e Ciência da Informação,Campinas, v.6, n. 2, p. 83-104, jan./jun. 2009- ISSN: 1678-765X. 
Definida como qualquer forma paga para promover produtos e serviços, a propaganda pode ser usada para melhorar a comunicação e esclarecer o público sobre os produtos e serviços da biblioteca. Posters, outdoors, cartazes, cartas e outros meios de comunicação utilizados pela área comercial podem ser empregados para este fim.

Teoricamente, a publicidade é diferenciada da propaganda por promover informações sobre o produto e serviços por meio de notícias gratuitas em jornais, televisão, rádio ou qualquer outro meio de comunicação de massa. No entanto, vê-se que os usuários dessas formas de promoção usam os dois conceitos como sinônimos.

De acordo com Kotler (1998, p. 264) a atmosfera é: “O espaço físico em que a organização produz ou entrega seus produtos e serviços, torna-se outro poderoso gerador de imagem”. Nos segmentos “não lucrativos”, a “atmosfera” não é considerada como importante. No entanto, para o caso da biblioteca, a atmosfera pode ser considerada como fator de promoção para incentivar o uso.

Sendo assim, a biblioteca deve manter o setor de referência, estantes, local de estudo de maneira que o leitor se sinta bem. O ambiente deve ser agradável, acolhedor e com outras características propícias para leitura, pesquisa ou qualquer outra atividade que possa ser exercida na biblioteca. O autor recomenda que o projeto da construção leve em consideração: o design interior, layout, cores, materiais e móveis ergonômicos que estimulem a oferta dos produtos e serviços da organização.

As grandes campanhas para lançamento de novos produtos fazem uso de todos os elementos da promoção, da seguinte maneira: convocam a imprensa, distribuem cartazes e outros impressos, colocam mensagens na televisão, rádios, jornais e revistas de grande circulação, organizam debates, oferecem brindes e cuidam da atmosfera por meio do arranjo do ambiente, equipe e outros detalhes que promovam o produto ou serviço.

Nos dias atuais, pode-se incluir a página da biblioteca na Internet como ambiente convidativo para o uso dos serviços e produtos de bibliotecas. As páginas das bibliotecas têm evoluído, pois muitas já entenderam que é necessário um planejamento do display das informações, uso adequado de cores, tamanho das letras, links que auxiliam a navegação e outros detalhes que tornam a página um ambiente agradável para a busca da informação.

(c) Revista Digital de Biblioteconomia e Ciência da Informação,Campinas, v.6, n. 2, p. 83-104, jan./jun. 2009- ISSN: 1678-765X. 


\subsection{Distribuição}

A acessibilidade à informação é o critério-chave para o planejamento de produtos e serviços de bibliotecas. Para tanto, é necessário considerar os fatores: tempo, lugar e posse. O critério acessibilidade está sempre presente nos estudos de uso e usuários de informação. As novas tecnologias incrementaram esse aspecto quanto às possibilidades de recuperar a informação. Tem-se percebido que o usuário, na busca da informação, faz a opção pela acessibilidade e, que, nem sempre assegura a mesma qualidade da informação encontrada numa unidade de informação. Figueiredo (1996, p. 245) chama a atenção dos bibliotecários para esse aspecto:

A aplicação das novas tecnologias da comunicação nas atividades de informação requer e/ ou motiva mudanças organizacionais, tanto nas estruturas quanto nas funções e operações das bibliotecas/ unidades de informação. Do ponto de vista dos usuários, essas tecnologias tornaram acessíveis maior número e melhores bases de dados para a realização de suas pesquisas, além de terem proporcionado a possibilidade de comunicação entre elas. (FIGUEIREDO, 1996, p. 245).

\section{A ADOÇÃo DO MARKETING PELA BIBLIOTECA DA PRESIDÊNCIA DA REPÚBLICA}

A Biblioteca da Presidência da República (BPR) foi criada no dia 18 de outubro de 1951, porém seu acervo tem origem na Biblioteca do Palácio do Catete. Em 1960, a Biblioteca foi transferida para a nova capital, Brasília. Em 1978, com a construção dos anexos do Palácio do Planalto, ela foi instalada no $1^{\circ}$ andar do Anexo 1 , onde se encontra até a presente data.

Por meio da análise de documentos histórico-administrativos, bem como pela atuação da Biblioteca nos últimos 10 anos é possível afirmar que a Biblioteca não possuía a oferta de informações alinhadas ao processo de tomada de decisão e às atividades profissionais e institucionais da organização.

Tal situação pode ser considerada um reflexo da inexistência de uma estrutura organizacional adequada, a ausência específica de rubrica para aquisição de acervo bibliográfico, a aquisição aleatória e descentralizada de obras, dentre tantos outros fatores.

(c) Revista Digital de Biblioteconomia e Ciência da Informação,Campinas, v.6, n. 2, p. 83-104, jan./jun. 2009- ISSN: 1678-765X. 
O ambiente físico da Biblioteca carecia de espaço para estudos em grupo, sala de reuniões, sala de higienização de livros. Além disso, o ambiente não dispunha de equipamentos que evitassem a proliferação de mofo, ruídos, piso adequado para a circulação de usuários e iluminação adequada para ambiente de estudo.

Apesar das dificuldades expostas, a Biblioteca conseguiu manter o acervo por meio de doações e intercâmbio de publicações. Foi propiciada uma mudança de cultura organizacional viabilizando a aquisição centralizada de material bibliográfico na Presidência da República (PR), evitando dessa forma a aquisição de materiais em duplicata e, conseqüentemente, evitando gastos excessivos ao erário público.

Entre novembro de 2004 e janeiro de 2005, foi realizado um estudo de usuários para verificar se as necessidades informacionais e se essas necessidades estavam atreladas às competências organizacionais da Presidência da República.

No período compreendido entre novembro/2003 a agosto/2005, a gestão da Biblioteca da Presidência da República (BPR) esteve sob coordenação da Diretoria de Gestão de Pessoas (DIGEP), época em que se obtiveram os seguintes resultados:

1 - realização do evento Biblioteca da Presidência da República na Era do Conhecimento, em comemoração ao Dia do Bibliotecário. Este acontecimento foi o marco para a transformação da BPR em um modelo de referência para as bibliotecas especializadas da Administração Pública Federal Direta;

2 - criação da identidade visual da Biblioteca. Fato que contribuiu para a imagem do setor e para a divulgação das suas ações, produtos e serviços;

3 - revisão do planejamento estratégico do setor, tendo como um dos objetivos torná-la também uma biblioteca virtual;

4 - inserção da BPR na estrutura organizacional da Casa Civil, a partir da criação de uma coordenação; 
5 - ampliação da força de trabalho com o intuito de implementar a nova missão e visão de futuro;

6 - participação da BPR no fórum de discussão das bibliotecas especializadas da administração pública federal direta, contribuindo para o papel de indutora na transformação gerencial das outras bibliotecas da Esplanada dos Ministérios;

7 - reforma e inauguração do novo ambiente físico, adotando o conceito de ergonomia.

Atualmente, a estrutura de trabalho da Biblioteca da Presidência da República leva em consideração o objetivo: promoção e expansão da cidadania e fortalecimento da democracia, conforme ilustra a figura a seguir. Logo, pode-se afirmar que a biblioteca está alinhada às atividades profissionais e institucionais da organização.

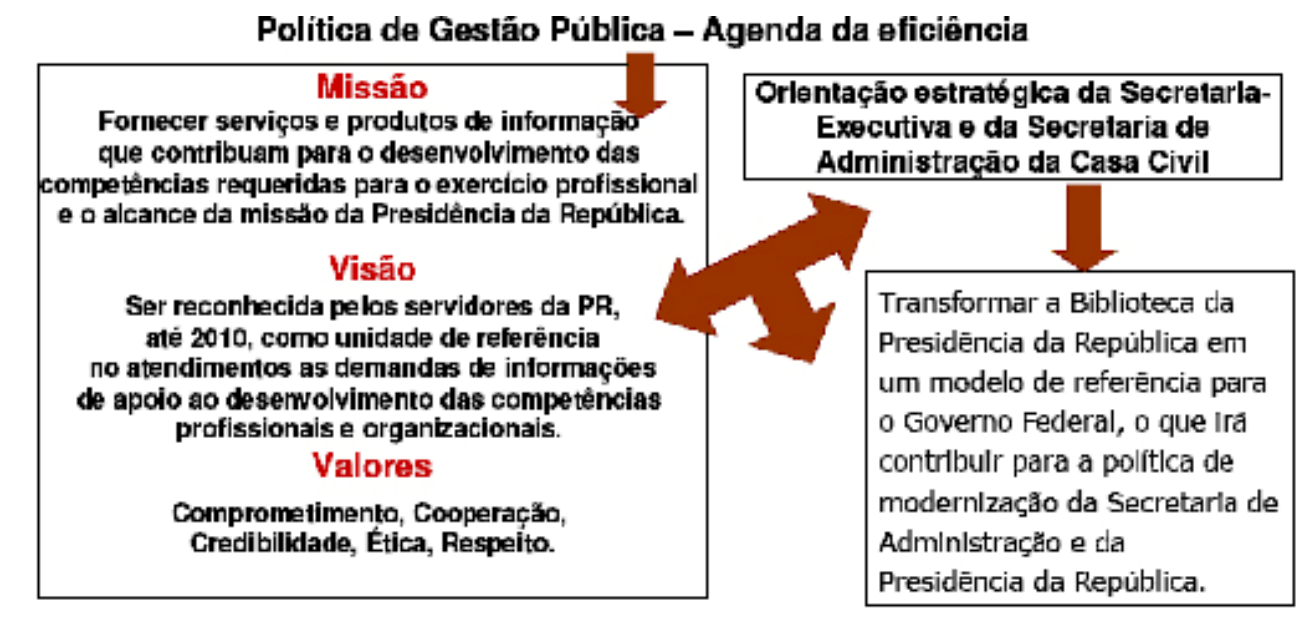

FIGURA 2 - POLÍTICA DE GESTÃO PÚBLICA - AGENDA DA EFICIÊNCIA

Fonte: BRASIL (2006)

A partir de 2004, várias inovações ocorreram na Biblioteca da Presidência da República. Internamente, a biblioteca organizou-se como uma unidade sistêmica ${ }^{1}$, que obedece ao ciclo de tratamento documental. Como em qualquer outro sistema, a BPR apresenta o conjunto de elementos interligados que se organizam em: entrada, processamento e saída.

1 “(...) Um conjunto de partes que interagem e funcionam como um todo". MAXIMIANO, Antonio César Amaru. 6.ed. Introdução à administração. São Paulo: Atlas, 2004. p. 62. 
Enquanto unidade sistêmica, a Biblioteca possui, como entrada do sistema, o macroprocesso de Seleção, Aquisição \& Intercâmbio. A Análise Técnica corresponde ao processamento e o Atendimento ao Usuário representa a saída do sistema. O macroprocesso de Serviços e Produtos de Informação é transversal a todos os macroprocessos da biblioteca e contribui para a saída do sistema. A Figura 3 ilustra a necessidade de sinergia entre os macroprocessos e com a coordenação da biblioteca. A figura representa uma engrenagem em funcionamento, ou seja, se um macroprocesso apresentar dificuldades, essas dificuldades serão refletidas nos demais macroprocessos.

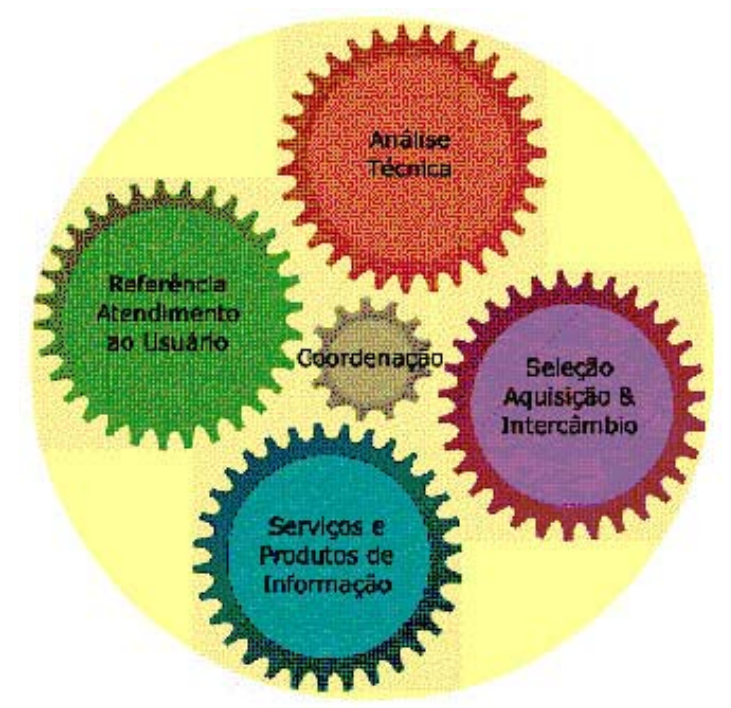

FIGURA 3 - MACROPROCESSOS DA BIBLIOTECA DA PRESIDÊNCIA DA REPÚBLICA Fonte: BRASIL (2006)

As inovações iniciadas em 2004 levaram em consideração a importância do marketing em unidades de informação, utilizando as atividades e instrumentos promocionais para atrair os usuários sobre os serviços oferecidos pela Biblioteca. Após três anos de utilização de técnicas promocionais, foi observado que “o emprego dessas técnicas trouxe 
resultados significativos para a promoção dos serviços dessa unidade de informação", conforme observação de Viana Neta (2006).

Assim, a Biblioteca da Presidência da República (BPR) procurou adaptar a "visão mercadológica” do marketing para satisfazer seu usuário. Logo, pode-se afirmar que a gestão atual da Biblioteca possui uma filosofia orientada para o marketing e que as atividades de promoção são planejadas de forma integrada. Os resultados da filosofia administrativa orientada para o marketing são nitidamente observados nas técnicas de promoção de: relações públicas, merchandising, propaganda, publicidade, venda pessoal, incentivos e atmosfera, conforme o estudo realizado por Viana Neta (2006).

No que se refere à atividade promocional de relações públicas, a biblioteca oferece: treinamento de usuários por meio do "Programa de Ambientação da Presidência da República”, ou toda vez que é solicitada. Além disso, a biblioteca possui uma padronização no atendimento ao usuário e sempre participa de eventos permanentes realizados pela Presidência da República, a exemplo citamos: "Semana Pensa Vida", “Semana do Servidor” e "Fóruns do Planalto”. Com exceção das atividades realizadas pela Presidência da República com o apoio da biblioteca, a unidade tem promovido eventos sociais, no dia do bibliotecário, para a classe de bibliotecários e profissionais afins. Em 2004, a comemoração do dia do bibliotecário foi marcada com o evento "A Biblioteca da Presidência da República na Era do Conhecimento”, em 2005, a comemoração do dia do bibliotecário foi marcada pela a "Reinauguração da Biblioteca da Presidência da República”, enfim em 2007, a comemoração do dia do bibliotecário foi marcada pelo evento "O Papel do Profissional da Informação na Gestão do Conhecimento" que contou com a presença de aproximadamente 300 pessoas e teve transmissão em rede nacional pela Radiobrás. Além dos eventos de comemoração do dia do bibliotecário, em outubro de 2005, a biblioteca realizou uma cerimônia de comemoração para o recebimento da certificação fornecida pelo Conselho Regional de Biblioteconomia $1^{\circ}$ Região.

No que diz respeito à atividade promocional de merchandising, a BPR dispõe de mostruário para exposições (display), realiza periodicamente diversas exposições (dia do livro, natal, arte e artesanato, exposição de trabalhos de crianças cadastradas no “Programa Escolas Irmãs”, “Arte Naiif” etc.). Além dessas iniciativas, durante a “Semana 
do Servidor", a biblioteca costuma participar do evento no stand da Secretaria de Administração para divulgar os serviços de informação prestados.

A atividade promocional de publicidade é exaustivamente realizada pelo setor de serviços e produtos de informação da BPR. Os eventos, as conquistas, como por exemplo, a da certificação digital, as campanhas de doação de livros para a formação da Biblioteca Myriam Pelles Ervilha - resultado da parceria com o "Programa Escolas Irmãs” e outras atividades. Essas ações são sempre divulgadas na Intranet da Presidência da República, bem como na Internet por meio dos sites: www.brasil.gov.br, $\underline{\text { www.abdf.org.br, }}$ www.crb1.org.br, www.ibict.br e em outros sites.

No que se refere à atividade promocional atmosfera, o estudo de Viana Neta (2006) verificou que a BPR possui sinalizações em todo o ambiente da biblioteca. A sinalização nas estantes é visualmente agradável e há adequação do espaço físico aos usuários. O espaçamento entre as estantes e os móveis foi projetado de forma a permitir o acesso de deficientes físicos, seguindo as orientações de acessibilidade recomendadas pela NBR 9050. Para os usuários deficientes físicos, a BPR possui cabines de estudo e terminais de computadores de uso coletivo, projetados ergonomicamente para atender às necessidades desses usuários. Além disso, a Presidência da República conta com rampa de acesso aos anexos e elevadores exclusivos para deficientes físicos.

Ainda no que diz respeito à atmosfera, a BPR oferece as seguintes facilidades: cabines individuais de estudo, mesas para estudo em grupo, sala para leitura de jornais, sala de higienização de documentos, capa para funcionários, sala de reunião com equipamentos de datashow, notebook, televisão, DVD, VHS e som para vinte pessoas.

Toda a biblioteca é monitorada por câmaras de segurança administradas por um sistema de segurança exclusivo da biblioteca. Além da segurança da biblioteca, há a segurança do acervo que conta com etiquetas especiais em suas páginas, evitando, dessa forma, que o usuário saia indevidamente com algum material bibliográfico.

O acervo bibliográfico não é protegido apenas por essas etiquetas magnéticas, há uma preocupação grande com a preservação do acervo. A temperatura da biblioteca é 
controlada e, entre as estantes, há esterilizadores de ar, bem como um piso especial antimofo e anti-ruído.

Sobre a atividade promocional de venda pessoal, o estudo de Viana Neta (2006) identificou que todos os funcionários usam crachá, além de jaleco (com a logomarca da biblioteca) que é utilizado durante o processo de higienização. Qualquer servidor da Biblioteca está apto atender com eficiência o usuário e orientá-lo quanto à utilização do acervo.

Sobre a atividade promocional de incentivos a Biblioteca oferece um conjunto de brindes aos seus visitantes. Todos os brindes têm como objetivo promover o uso da biblioteca, incentivar a leitura e a preservação do acervo. A BPR dispõe um kit de brindes que é composto por: uma pasta da Biblioteca, bloco de anotações, marcador de livro e folder da Biblioteca. Além disso, em 2005 foram produzidos vários CD’s-ROM que representam por meio de imagens a reforma da Biblioteca realizada em 2004. Portanto, em alguns casos, é acrescentado ao kit do visitante o CD.

Ainda no que diz respeito à atividade de incentivos, vale a pena destacar que a BPR distribui materiais publicitários durante os eventos por ela realizados. Pode-se citar, por exemplo, o evento “A Biblioteca da Presidência da República na Era do Conhecimento”. Os participantes ganharam uma réplica da tela Retrato de Rodolpho Josetti - 1928 de Cândido Portinari e um marcador de livro com a miniatura da tela.

Em 2005, durante a cerimônia de "Reinauguração da Biblioteca", os participantes do evento ganharam os CD’s que refletiam as etapas da reforma. Em 2007, durante o evento “O Papel do Profissional da Informação na Gestão do Conhecimento” os participantes ganharam a réplica da tela - Leitura - 1892 de José Ferraz de Almeida Júnior e um marcador de livro com a miniatura da tela e a frase: “incentive a leitura e a visita à Biblioteca”.

A atividade promocional de propaganda não é realizada pela BPR. No entanto, a mídia costuma realizar matérias sobre a Biblioteca. 


\section{CONCLUSÃO}

Percebe-se, a partir das experiências relatadas, que o marketing pode ser um instrumento apropriado para a unidade de informação ficar conectada com o seu usuário e prestar serviços apropriados para cada segmento. No caso da BPR, pode-se concluir que a técnica foi empregada, após um planejamento cuidadoso para melhorar e ampliar a prestação de serviços e oferecer um ambiente adequado e atrativo para os seus usuários.

No entanto, foi observado que a BPR ainda não utiliza a web para divulgar seus serviços e produtos de informação. Por meio de um /website/, a biblioteca poderia alcançar aqueles que não conhecem os seus serviços e produtos. A respeito do assunto, ressalta-se que a integração entre o planejamento estratégico e o marketing oferece para o gerente de unidades de informação amplas possibilidades de atender melhor o usuário da sua unidade de informação. Por sua vez, a Internet atrai usuários potenciais e auxilia o relacionamento entre a biblioteca e seu usuário real. Assim, a triangulação das técnicas de planejamento estratégico, marketing e utilização da tecnologia da informação (nesse caso a Internet) podem promover a visibilidade da biblioteca e contribuir para o reconhecimento de suas ações como provedora de acesso à informação e ao conhecimento.

\section{REFERÊNCIAS}

AMARAL, S. A. Marketing e gerência de biblioteca. Revista de Biblioteconomia de Brasília, Brasília, v.18, n.2, p.311-317, 1990.

. What libraryy manager's know about marketing: a study of Brazilian geoscience and mineral technology libraries. Information Development, Londres, v.8, n.2, p.90-94, 1992a.

Do marketing á auditoria em serviços de informação. Revista Brasileira de Biblioteconomia e Documentação, São Paulo, v.25, n.3/4, p.18-28, 1992 b.

Atividades de marketing na promoção de serviços de informação: pesquisa sobre o SONAR-INIS e o SERVIR-INIS do CIN/CNEN. Perspectivas em Ciência da Informação, Belo Horizonte, v. 6, n. 1, p. 75-96, 2001.

(c) Revista Digital de Biblioteconomia e Ciência da Informação,Campinas, v.6, n. 2, p. 83-104, jan./jun. 2009- ISSN: 1678-765X. 
Marketing da informação na Internet: ações de promoção. Campo Grande: UNIDERP, 2004. 330 p.

ANDREASEN, A. R. O avanço de marketing para bibliotecas. In: SILVEIRA, A. (Org.). Marketing em bibliotecas e serviços de informação: textos selecionados. Brasília: IBICT, 1987, p. 37-64.

BAPTISTA, S. G. A contribuição da estratégia do método de marketing para solucionar problemas de baixo índice de acervo de freqüência em bibliotecas: estudo de caso. 1985. 103 f. Dissertação (Mestrado em Biblioteconomia e Documentação) Departamento de Biblioteconomia, Universidade de Brasília, Brasília, 1985.

Aplicação de marketing em bibliotecas e serviços de informação. Revista de Biblioteconomia de Brasília, v.16, n.1, p.95-111, jan./jun.1988.

BAX, M. P. As bibliotecas na web e vice-versa. Perspectivas em Ciência da Informação, Belo Horizonte, v.3, n.1, p.5-20, jan./jun. 1998.

BRASIL. Presidência da República. Coordenação Geral de Documentação e Informação. Coodenação de Biblioteca. Biblioteca da Presidência da República: relatório de gestão 2005. Brasília, 2006. 22 p., il. color.

CHURCHILL JR., Gilbert A. PETER, J. Paul. Marketing: criando valor para os clientes. São Paulo: Saraiva, 2003.

CORRALL, S. Strategic planning for library and information services. London: ASLIB, 1994. 50 p.

CRONIN, B. From paradigm to pratice: the logic of promotion. Aslib Proceedings, v.33, n. 10, p.3382-392, oct. 1981.

COSTA, M. M. O Site da Biblioteca central da Universidade de Brasília como instrumento promocional: sua concepção. 2001. 58 f. Monografia. (Graduação em Biblioteconomia) - Universidade de Brasília, 2001.

FIGUEIREDO, N. Novas tecnologias: impacto sobre a formação de coleções. Perspectivas em Ciência da Informação, Belo Horizonte, v.1, n.2, p.245-254, jul./dez. 1996.

FORREST, C. Segmenting the library marketing, reaching out the user community by reaching across the organizations. Georgia Library Quartely, v. 42, p.4-7, 2005.

KOTLER, P. Marketing para organizações que não visam o lucro. São Paulo: Atlas, 1978, $430 \mathrm{p}$ 
Administração de marketing: análise, planejamento, implementação e controle. 5.ed. São Paulo: Atlas, 1998. 725 p.

. Marketing para o século XXI: como criar, conquistar e dominar mercados. São Paulo: Futura, 1999. 305 p.

LIMA, A.B.A. Estudo de usuários de bibliotecas: aproximação crítica. Ciência da Informação, Brasília, v.21, n.3, p.173-185, 1992.

MANZO, J. M. Fundamentos de marketing. 4. ed. Rio de Janeiro: Zahar, 1982, p. 41.

VIEIRA, B. L. A.; NIQUE, W. M. Comércio eletrônico via internet: entendendo a internet como canal de compra. In: ENANPAD, 23., 1999, Foz do Iguaçu. Anais... Foz do Iguaçu: Anpad, 1999. Disponível em http://www.anpad.org.br/evento.php?acao=trabalho\&cod_edicao_subsecao=52\&cod_eve nto_edicao=3\&cod_edicao_trabalho=3361 Acesso em: 20/09/2007.

SILVEIRA, A. Marketing em sistema de informação: visão geral. Ciência da Informação, Brasília, v. 15, n. 1, p.45-52, 1986.

Marketing em bibliotecas universitárias: levantamento bibliográfico seletivo e anotado - 1970/1984. Cadernos do CED, Florianópolis, v. 4, n. 10, p.132-142, 1987.

VASSOS, T. Marketing estratégico na internet. São Paulo: Makron Books, 1997. 303p.

VIANA NETA, M. A. V. A utilização das técnicas de promoção de marketing em unidades de informação: o caso da Biblioteca da Presidência da República. 2006. 49 f. Monografia (Graduação em Biblioteconomia) - Universidade de Brasília, 2006. 


\section{Sofia Galvão Baptista}

Professora, Adjunto 4, do Departamento de Ciência da Informação da Universidade de Brasília. sofiag@unb.br

\section{Maíra Murrieta Costa}

Bacharel em Biblioteconomia (UnB), especialistas em Administração de Sistemas de Informação (FGV). Mestranda em Ciência, Gestão e Tecnologia da Informação pela UFPR.

mairamurrieta@gmail.com

\section{Maria Altair Vilanova Viana Neta}

Aluna de Biblioteconomia e autora da monografia (trabalho de conclusão de curso) que relata a experiência da biblioteca da Presidência da República com os instrumentos de promoção. gracinhadf18@yahoo.com.br

Recebido em: 16/04/2008

Aceito para publicação em: jul/2008 